\title{
Copper alloys to prevent bacterial biofilm formation on touch surfaces
}

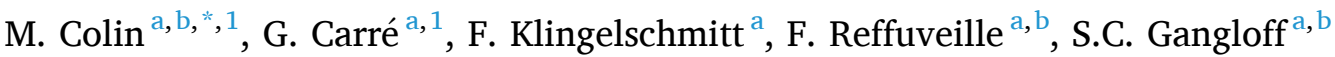 \\ ${ }^{a}$ Université de Reims Champagne-Ardenne, EA 4691 Biomatériaux et Inflammation en site Osseux (BIOS), SFR CAP-Santé, France \\ ${ }^{\mathrm{b}}$ Université de Reims Champagne-Ardenne, UFR de Pharmacie, Service de Microbiologie, France
}

\section{A R T I C L E I N F O}

\section{Keywords:}

Biofilm

Copper alloys

Touch surfaces

Artificial aging

\begin{abstract}
A B S T R A C T
Copper alloys surfaces have been proposed as a promising solution to avoid microbial contamination of surfaces but their antibiofilm effect is still unclear. All copper alloys tested have demonstrated efficient antibiofilm activity against Methicillin-resistant Staphylococcus aureus (MRSA) and Pseudomonas aeruginosa, with differences between alloys. The artificial aging of copper alloys led to variable effects on the bacterial adhesion, depending on alloy. The results highlighted the promising antibiofilm activity of various copper alloys and suggest that the alloy composition is an essential parameter in this activity.
\end{abstract}

\section{Introduction}

Currently, the healthcare associated infections (HAIs) remain a major concern, as their prevalence is still oscillating around $6 \%$ in Europe and 4\% United-States of America [1,2]. Pathogens such as methicillin-resistant Staphylococcus aureus (MRSA), involved in HAIs can spread to patients through the environment where bacteria, viruses and fungi can colonize inanimate surfaces and persist for hours to months [3].

S. aureus and Pseudomonas aeruginosa (PA) are well known for their strong abilities to form biofilm on various surfaces. This lifeform confers high protection against numerous external stress factors like antibiotics [4] or disinfectants [5]. Thus, pathogens can persist under biofilm form on hospital hard surfaces [6] where they can resist to regular disinfection and thereby represent a permanent risk.

To counteract pathogen survival on touch surfaces, several solutions have been proposed [7]. Among these solutions, the use of copper stood out as the most promising. Metallic surfaces made of pure copper or copper alloys demonstrated strong and inherent antimicrobial properties [8] against bacteria, viruses and fungi [9-11]. The in-use efficiency of metallic copper against bacterial contaminations has been confirmed in healthcare facilities [12,13].

However, the efficiency of copper touch surfaces to prevent biofilm formation has not been investigated yet. Here, the formation of MRSA and PA biofilms was studied on various copper alloys, and the effect of artificial aging of the alloy samples toward their antibiofilm activities was also tested.

\section{Experimental}

\subsection{Metallic samples}

Seven copper alloys (Table 1) provided by Lebronze alloys were manufactured in pieces of 40 by 8 by $8 \mathrm{~mm}\left(1408 \mathrm{~cm}^{2}\right)$. Stainless steel (SS) coupons of X2CrNi18-09 (AISI 304L) measuring 50 by 7 by $1 \mathrm{~mm}$ $\left(814 \mathrm{~cm}^{2}\right)$ were used as control. A0 was used as referent copper alloy in preliminary tests as it has previously been used in the manufacturing of door handles installed in five healthcare facilities $[12,13]$. Before tests, copper alloy samples were brushed with abrasive pad for one minute, then rinsed with 20 spray of deionized water. Finally, excess water was removed by applying a paper towel gently.

\subsection{Artificial aging}

Metallic samples were immersed for two minutes in a solution of Aniosurf Premium disinfectant (Laboratoires Anios) diluted at $0.25 \%$ in distilled water. Samples were then rinsed with 20 sprays of deionised water and water excess on samples was eliminated by applying a paper towel gently. Samples were then incubated at room temperature for one hour (latent phase). Eighteen cycles of immersion, washing, drying and latent phase were performed successively.

\subsection{Bacterial culture}

MRSA CIP 103.811 or PA CIP 82.118 strains from Institut Pasteur

\footnotetext{
* Corresponding author at: Université de Reims Champagne-Ardenne, EA 4691 Biomatériaux et Inflammation en site Osseux (BIOS), SFR CAP-Santé, France.

E-mail address: marius.colin@univ-reims.fr (M. Colin).

1 Both authors contributed equally to the paper.
} 
Table 1

Chemical composition of the seven copper alloys tested.

\begin{tabular}{llllllll}
\hline & Alloy 0 & Alloy 1 & Alloy 2 & Alloy 3 & Alloy 4 & Alloy 5 & Alloy 6 \\
\hline$\% \mathrm{Cu}$ & 92.15 & 68.5 & 94 & 92.4 & 92.5 & 85 & 92.25 \\
$\% \mathrm{Zn}$ & $/$ & 11 & 5 & 5 & $2-7.5$ & 15 & $/$ \\
$\% \mathrm{Al}$ & 7.75 & 2.5 & 1 & 1 & $/$ & $/$ & 7.75 \\
$\% \mathrm{Mn}$ & $/$ & 18 & $/$ & $/$ & $/$ & $/$ & $/$ \\
$\% \mathrm{Fe}$ & $/$ & $/$ & $/$ & 1 & $0.5-3$ & $/$ & $/$ \\
$\% \mathrm{Si}$ & $/$ & $/$ & $/$ & 0.6 & $0.2-4$ & $/$ & $/$ \\
$\% \mathrm{Ag}$ & 0.1 & $/$ & $/$ & $/$ & $/$ & $/$ & $/$ \\
\hline
\end{tabular}

collection were cultured overnight in tryptic soy broth (TSB) and then subcultured for $4 \mathrm{~h}$. Bacteria were then washed and concentrated by centrifugation (1800g) to reach a concentration around $10^{10} \mathrm{CFU} / \mathrm{mL}$.

\subsection{Determination of basic antibacterial activity}

Three independent $10 \mu \mathrm{L}$ droplets of the bacterial suspension were inoculated on each metal sample. Samples were then incubated at room temperature for two hours. Surviving bacteria were then collected by applying a sterile cotton swab moistened and resuspended in $7.5 \mathrm{~mL}$ of peptone water (PW) through a two minutes sonication and vortexing. Serial dilutions were exponentially seeded on tryptic soy agar (TSA) and incubated at $37^{\circ} \mathrm{C}$ for $24 \mathrm{~h}$ before enumeration of colony forming units (CFU).

\subsection{Determination of antibiofilm activity}

A unique $10 \mu \mathrm{L}$ droplet of bacterial suspension was inoculated on each metal sample. Metallic samples were dried for $30 \mathrm{~min}$ and then transferred in $50 \mathrm{~mL}$ sterile tubes containing $15 \mathrm{~mL}$ of PW or TSB and incubated at $37{ }^{\circ} \mathrm{C}$ for $24 \mathrm{~h}$ to allow biofilm growth. Metallic samples were then washed in PBS and transferred in new $50 \mathrm{~mL}$ sterile tubes containing $15 \mathrm{~mL}$ of PW. Then, adherent bacteria where resuspended through a five minutes sonication and vortexing. Serial dilutions were exponentially seeded on TSA and incubated at $37^{\circ} \mathrm{C}$ for $24 \mathrm{~h}$. Results were expressed as CFU per $\mathrm{cm}^{2}$ of metallic sample.

\subsection{Statistical analysis}

All tests were performed in triplicate, each including three technical replicates. Comparison between conditions were analysed using the non-parametric Mann-Whitney test on GraphPad Prism 5 Software. The results were considered as statistically significant when $P<0.05$.

\section{Results and discussion}

\subsection{Biofilm formation on stainless steel and a copper alloy}

PW was used to mimic low soiling while TSB, which contains a high level of nutrients, was used to mimic an extreme soiling of the surface and provided pro-bacterial environment (Fig. 1). Bacteria highly adhered to SS, with a mean $8.0 \times 10^{4} \mathrm{CFU} / \mathrm{cm}^{2}$ when incubated in PW and $1.3 \times 10^{6} \mathrm{CFU} / \mathrm{cm}^{2}$ when incubated in TSB. On A0, biofilms were rarely formed when samples were incubated in PW. Results were different in TSB, where biofilms systematically formed on A0 with a mean of $3.8 \times 10^{4} \mathrm{CFU}$, which is $1.6 \mathrm{log}$ lower than on SS. Surprisingly, biofilms could be formed on a copper alloy immerged in media that promotes bacterial growth. However, TSB is a very rich medium in which metallic samples are totally immersed. This represents extreme pro-biofilm conditions that are unlikely to happen in in-use reality of touch surfaces. Oxidation and corrosion on the surface may take place at higher levels in aqueous media than in dry conditions [14] resulting in a lowering of the antibiofilm effects.

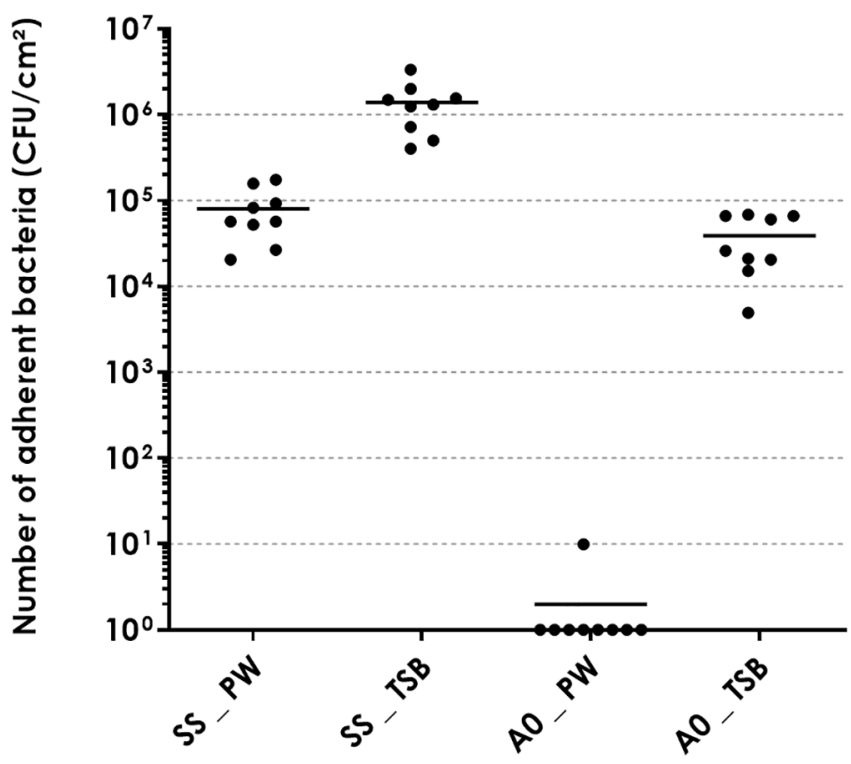

Fig. 1. MRSA biofilm formation on metallic samples. Enumeration of adherent bacteria on stainless steel (SS) and Alloy 0 after $24 \mathrm{~h}$ of immersion in peptone water (PW) or tryptic soy broth (TSB). Results from every condition were significantly different to all other conditions, excepted for the comparison of SS_PW and A0_TSB.

\subsection{Biofilm formation on various copper alloys}

All the copper alloys demonstrated a significant antibiofilm effect against both MRSA and PA strains, compared to SS (Fig. 2). A0 appeared to display the weaker antibiofilm activity against both strains compared to other alloys. Interestingly, A4 $(92.5 \% \mathrm{Cu})$ displayed far better antibiofilm activity toward MRSA than A0 $(92.15 \% \mathrm{Cu})$, despite their very close percentage of copper. It was already demonstrated that alloys with lower copper percentage can present higher antibacterial, antiviral or antifungal activities [9-11] and authors pointed out the role of minor elements. A4 was, by far, the most effective alloy against both MRSA and PA adhesion, with significant effects compared to A1. A2 and A5 lowered the adhesion of MRSA compared to A0 and A1, but were less efficient against PA. Conversely, A6 presented the highest number of adhered MRSA (although values were very variable) while this alloy was particularly effective against PA adhesion. These results suggest that different copper alloys may act on bacterial biofilm through different mechanisms depending on the type of bacteria, confirming the already observed difference in survival of Gram-negative and Gram-positive bacteria tested on the same alloys [15]. Studying the antibiofilm effect of numerous copper alloys against a wider range of bacteria could bring more information on this matter.

\subsection{Effect of artificial aging}

In healthcare facilities, the regular disinfection and use of copper touch surfaces like door handles can lead to a progressive loss of their antibacterial activity [13]. This was reproduced here by artificial aging. Bacterial viability on SS was not affected by the aging process, validating the absence of remaining effect of the disinfectant used in the aging solution (Fig. 3A). Artificial aging significantly reduced A0 basic antibacterial activity as seen in the healthcare facilities in-use situation. Focusing on biofilm, significantly less bacteria adhered on aged A0, A1 and A6 compared to non-aged (Fig. 3B) while no significant difference was detected for A2, A3 and A4. Finally, A5 was the only alloys for which the adherent bacteria number was significantly higher on aged samples. These results suggest that various alloys react differently to recurrent disinfection. 

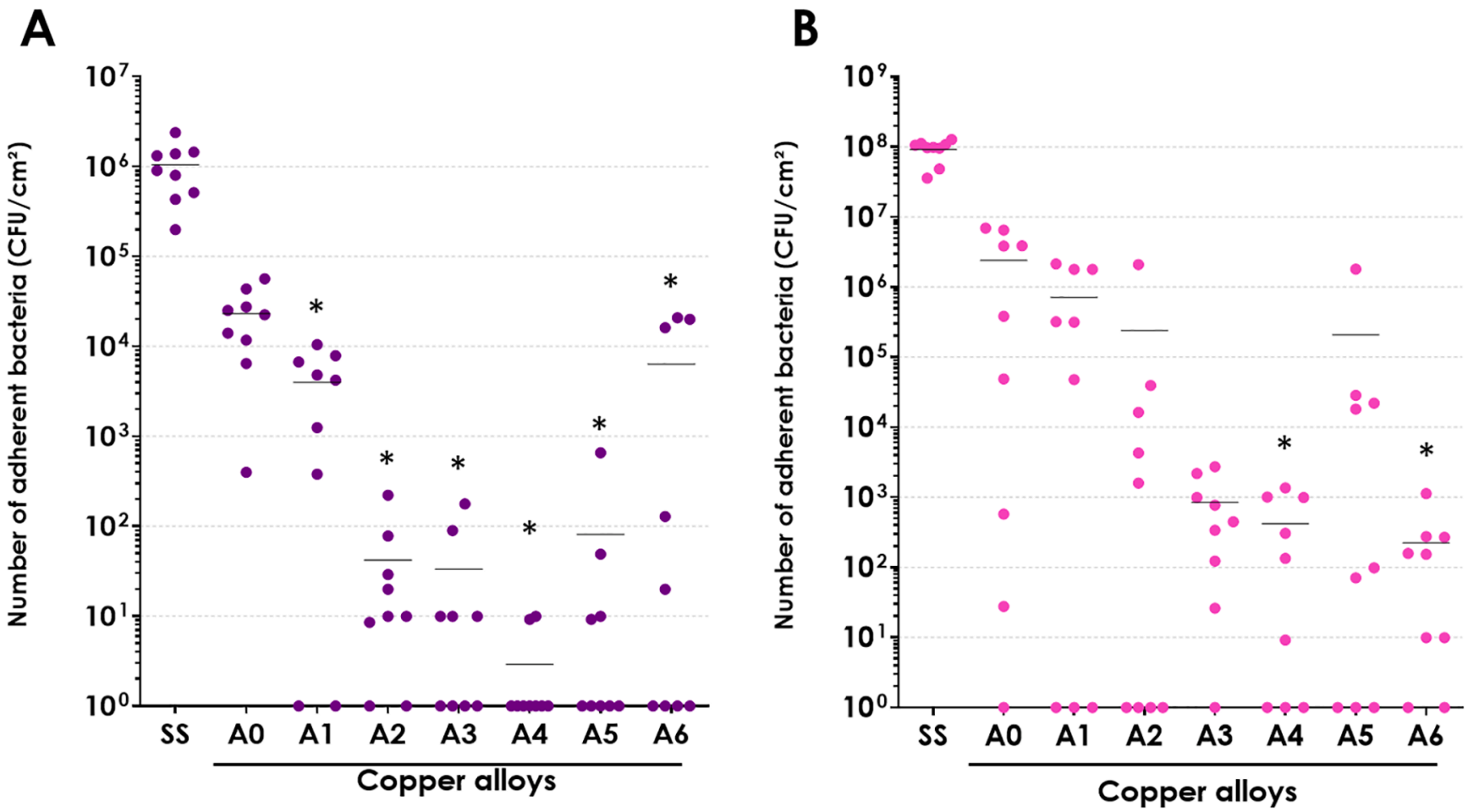

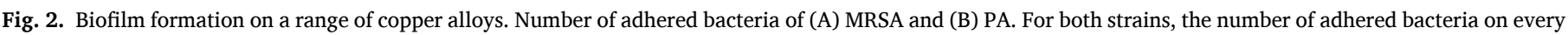
copper alloy was significantly lower than on SS. * indicate a significant statistical difference compared to A0.
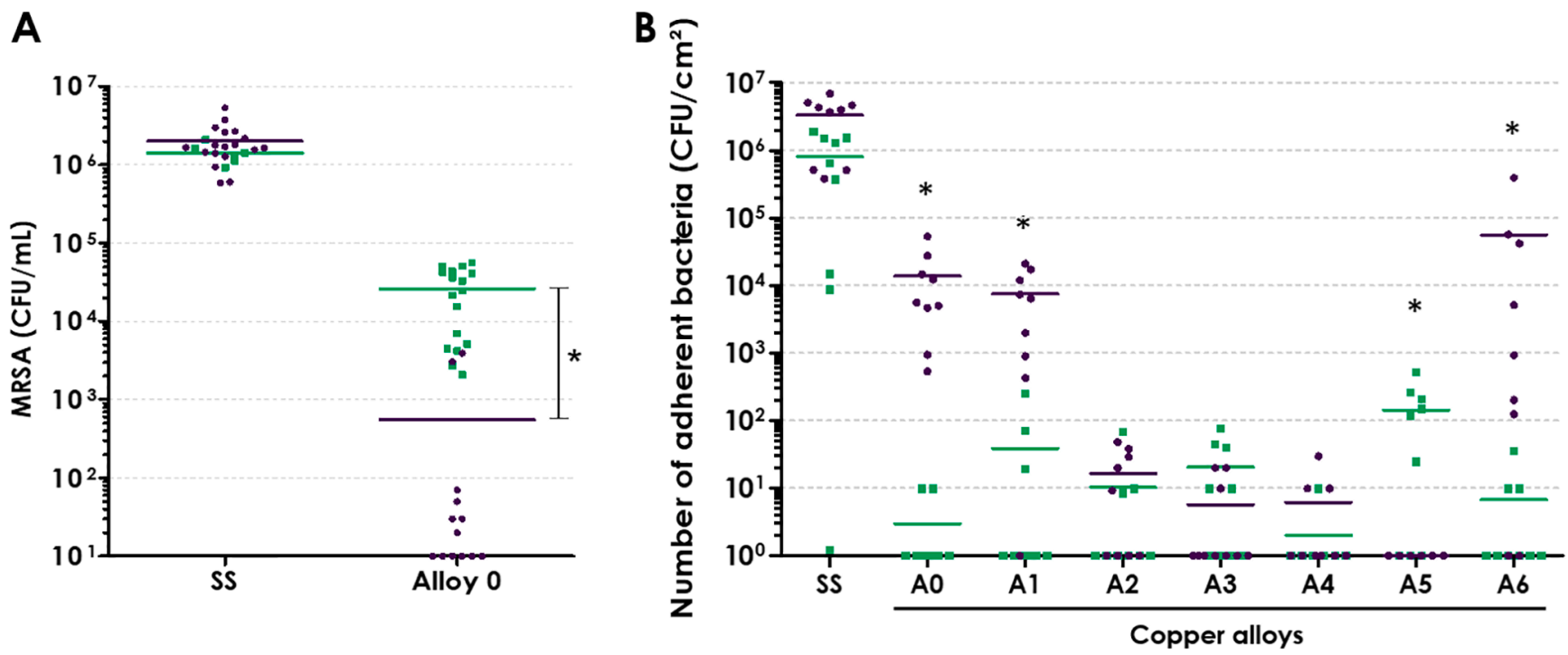

Fig. 3. Effects of artificial aging on antibacterial and antiadhesive activities of metallic samples against MRSA. (A) Determination of basic antibacterial activity of SS and $\mathrm{A} 0$ by numeration of remaining bacteria on non-aged (blue points) or aged (green squares) samples after a $2 \mathrm{~h}$ contact. (B) Determination of the antiadhesive activity of all the alloys by numeration of adhered bacteria on non-aged (blue points) or aged (green squares) samples after $24 \mathrm{~h}$ in TSB. * indicate significant differences between aged and non-aged samples.

\section{Conclusion}

Very specific artificial conditions were settled to challenge the biofilm formation on copper. The activity against biofilm formation was highlighted for all the seven copper alloys. However, some alloys, especially A4, presented a stronger antibiofilm activity against both bacterial strains and an improvement of this activity through repeated disinfection. As the percentage of copper in the alloy is not the only important parameter, studies exploring various alloy compositions will be welcomed to unravel the effect of minor compounds on antibacterial and antibiofilm properties. Some copper alloys appear as promising candidates and the selection of the best alloy is thus essential to fight against biofilm formation on healthcare touch surfaces.

\section{CRediT authorship contribution statement}

M. Colin: Validation, Formal analysis, Visualization, Writing original draft, Writing - review \& editing. G. Carré: Conceptualization, Methodology, Formal analysis, Investigation, Visualization. F. Klingelschmitt: Methodology, Investigation. F. Reffuveille: Validation. S. 
C. Gangloff: Conceptualization, Validation, Supervision, Project administration, Funding acquisition, Writing - original draft, Writing review \& editing.

\section{Declaration of Competing Interest}

The authors declare that they have no known competing financial interests or personal relationships that could have appeared to influence the work reported in this paper.

\section{Acknowledgments}

This work, as well as F.K., G.C. and M.C. were financially supported by the European Regional Development Fund and by the Region Grand Est through the CUPROCARE project.

\section{References}

[1] European Centre for Disease Prevention and Control, Point prevalence survey of healthcare-associated infections and antimicrobial use in European acute care hospitals :2011 2012, Publications Office, LU, 2013. https://data.europa.eu/doi/ 10.2900/86011 (accessed May 4, 2021)
[2] S.S. Magill, J.R. Edwards, W. Bamberg, Z.G. Beldavs, G. Dumyati, M.A. Kainer, R. Lynfield, M. Maloney, L. McAllister-Hollod, J. Nadle, S.M. Ray, D.L. Thompson, L.E. Wilson, S.K. Fridkin, N. Engl. J. Med. 370 (2014) 1198-1208.

[3] J.A. Otter, S. Yezli, J.A.G. Salkeld, G.L. French, Am. J. Infect. Control 41 (2013) S6-S11.

[4] F. Lamret, M. Colin, C. Mongaret, S.C. Gangloff, F. Reffuveille, Antibiotics 9 (2020) 547.

[5] A. Bridier, R. Briandet, V. Thomas, F. Dubois-Brissonnet, Biofouling 27 (2011) 1017-1032.

[6] K. Johani, D. Abualsaud, D.M. Costa, H. Hu, G. Whiteley, A. Deva, K. Vickery, J. Infect. Public Health 11 (2018) 418-424.

[7] L. Cobrado, A. Silva-Dias, M.M. Azevedo, A.G. Rodrigues, Eur. J. Clin. Microbiol. Infect. Dis. 36 (2017) 2053-2062.

[8] G. Grass, C. Rensing, M. Solioz, Appl. Environ. Microbiol. 77 (2011) 1541-1547.

[9] S. Chyderiotis, C. Legeay, D. Verjat-Trannoy, F. Le Gallou, P. Astagneau, D. Lepelletier, Clin. Microbiol. Infect. 24 (2018) 1130-1138.

[10] D. Quaranta, T. Krans, C.E. Santo, C.G. Elowsky, D.W. Domaille, C.J. Chang, G. Grass, Appl. Environ. Microbiol. 77 (2011) 416-426.

[11] S.L. Warnes, Z.R. Little, C.W. Keevil, MBio 6 (2015) e01697-15.

[12] M. Colin, E. Charpentier, F. Klingelschmitt, C. Bontemps, C. De Champs, F. Reffuveille, S.C. Gangloff, J. Hosp. Infect. 104 (2020) 283-292.

[13] M. Colin, F. Klingelschmitt, E. Charpentier, J. Josse, L. Kanagaratnam, C. De Champs, S. Gangloff, Materials 11 (2018) 2479.

[14] J. Elguindi, S. Moffitt, H. Hasman, C. Andrade, S. Raghavan, C. Rensing, Appl Microbiol. Biotechnol. 89 (2011) 1963-1970.

[15] S.L. Warnes, V. Caves, C.W. Keevil, Environ. Microbiol. 14 (2012) 1730-1743. 